Jpn. J. Human Genet. 32, 49-50, 1987

\title{
Dir Ins(9)(q34.3q22.1q31.3) or Inv Ins(9)(q34.3q22.3q21.2)?
}

To the Editor:

Dr. Kajii and his colleagues have studied a large kindred, in which apparently the same chromosome rearrangement as in our report (Narahara et al., 1986) is segregating, suggesting that a karyotype of inversion carriers is invins(9)(q34.3q22.3 $\mathrm{q} 21.2)$ instead of $\operatorname{dir}$ ins(9)(q34.3q22.1q31.3). Our reply to them is as follows: First, the two kindreds are probably related to each other, although their common ancestral origin is yet to be detected. Second, it seems very difficult to identify the precise breakpoints of such a complex rearrangement, because the short segment involved in the insertional translocation is in the region showing mirror-image banding patterns. Results of conventional G- and R-banding were compatible with either invins(9)(q34.3q22.3q21.2) or $\operatorname{dir} \operatorname{ins}(9)(\mathrm{q} 34.3 \mathrm{q} 22.1 \mathrm{q} 32)$, but analysis of chromosomes at the level of near 850 bands per haploid set suggested that dir ins(9) $(\mathrm{q} 34.3 \mathrm{q} 22.1 \mathrm{q} 31.3)$ is more likely than inv ins $(9)(\mathrm{q} 34.3 \mathrm{q} 22.31 \mathrm{q} 21.2)$. The conclusion of which interpretation is correct has to await a study of dosage effect of a gene whose locus is mapped to the region in question. Third, intrachromosomal shift is not absolutely rare, eleven cases having been described (Table 1). Of these, five cases had inverted insertion, one had direct insertion and the remaining five had insertion of unknown direction owing to the shortness of the inserted segments. In all but one (Grass et al., 1981), the three-breakpoint-rearrangements were ascertained through recombinant products. Intrachromosomal shift, inverted or direct, would yield two loops during meiosis 1, one involving the inserted segment and the other the interposing (non-insertional) segment. An odd number of crossing-over in the latter loop would result in duplication or deficiency of the inserted segment, while that in the former loop would produce various types of recombinants, depending upon

Table 1. Reported cases with intrachromosomal shifts.

\begin{tabular}{|c|c|c|}
\hline Reference & Karyotype & Reason for ascertainment \\
\hline Therkelsen et al. (1973) & $\operatorname{dir} \operatorname{ins}(2)(\mathrm{q} 34 \mathrm{p} 13 \mathrm{p} 24)$ & Recombinant $(\operatorname{Rec})$ dup $2 \mathrm{p}$ \\
\hline Palmer et al. (1977) & inv ins $(1)(\mathrm{p} 22 \mathrm{q} 41 \mathrm{q} 25)$ & Rec dup lq \\
\hline Pan et al. (1977) & ins $(1)(\mathrm{p} 32 \mathrm{q} 25 \mathrm{q} 31)$ & Rec dup $1 \mathrm{q}$ and del $1 \mathrm{q}$ \\
\hline Miller et al. (1979) & $\operatorname{ins}(7)(\mathrm{p} 15 \mathrm{p} 21 \mathrm{q} 22)$ & Rec del $7 p$ and dup 7p \\
\hline Strobel et al. (1980) & inv ins $(11)(q 14.5 p 14.2 p 11.2)$ & Rec del $11 p$ and dup $11 p$ \\
\hline Wyandt et al. (1980) & inv ins(3)(p25.5p21.1p13.5) & Rec del $3 p$ \\
\hline Grass et al. (1981) & $\operatorname{ins}(X)(p 11 q 22 q 24)$ & Infertility \\
\hline Allderdice et al. (1983) & inv ins(9) (q22.1q34.3q34.1) & Rec dup 9q and del 9q \\
\hline Cohen et al. (1983) & ins(16) (q13pl1p13) & Rec dup $16 p$ \\
\hline Pai et al. (1983) & ins $(2)(\mathrm{p} 13 \mathrm{q} 31 \mathrm{q} 33)$ & Rec del $2 q$ \\
\hline Martin et al. (1985) & inv ins $(5)(p \mid 3 q 22 q 33)$ & Rec dup 5q \\
\hline
\end{tabular}


the direction of insertion. The exclusive occurrence of recombinants with pure deficiency or duplication of the inserted segments among the kindreds so far reported (Table 1) may indicate another possibility that the inserted segment and its homologue are omitted from meiotic pairing without forming a loop. Unfortunately, there has been no meiotic study of carriers with intrachromosomal shifts.

\section{REFERENCES}

Allderdice, P.W., Eales, B., Onyett, H., Sprague, W., Henderson, K., Lefeuvre, P.A., and Pal, G. 1983. Duplication 9q34 syndrome. Am. I. Hum. Genet. 35: 1005-1019.

Cohen, M.M., Lerner, C., and Balkin, N.E. 1983. Duplication of $16 \mathrm{p}$ from insertion of $16 \mathrm{p}$ into $16 q$ with subsequent duplication due to crossing over within the inserted segment. Am.J. Med. Genet. 14: 89-96.

Grass, F.S., Schwartz, R.P., Deal, J.O., and Parke, J.C. 1981. Gonadal dysgenesis, intra-X chromosome insertion, and possible position effect in an otherwise normal female. Clin. Genet. 20: 28-35.

Martin, N.J., Cartwright, D.W., and Harvey, P.J. 1985. Duplication $5 q(5 q 22 \rightarrow 5 q 33)$ : From an intrachromosomal insertion. Am. J. Med. Genet. 20: 57-62.

Miller, M., Kaufman, G., Reed, G., Bilenker, R., and Schinzel, A. 1979. Familial, balanced insertional translocation of chromosome 7 leading to offspring with deletion and duplication of the inserted segment, $7 \mathrm{p} 15 \rightarrow 7 \mathrm{p} 21 . \quad$ Am. J. Med. Genet. 4: 323-332.

Narahara, K., Takahashi, Y., Kikkawa, K., Wakita, Y., Kimura, S., and Kimoto, H. 1986. Assignment of $\mathrm{ABO}$ locus to $9 \mathrm{q} 31.3 \rightarrow \mathrm{qter}$ by study of a family in which an intrachromosomal shift involving chromosome 9 is segregating. Jpn. J. Human Genet. 31: $289-296$.

Pai, G.S., Rogers, J.F., and Sommer, A. 1983. Identical multiple congenital anomalies/mental retardation (MCA/MR) syndrome due to del(2) (q32) in two sisters with intrachromosomal insertional translocation in their father. Am. J. Med. Genet. 14: 189-195.

Palmer, C.G., Christian, J.C., and Merritt, A.D. 1977. Partial trisomy 1 due to a "shift" and probable location of the Duffy (Fy) locus. Am. J. Hum. Genet. 29: 371-377.

Pan, S.F., Fatora, S.R., Sorg, R., Garver, K.L., and Steele, M.W. 1977. Meiotic consequences of an intrachromosomal insertion of chromosome No. 1: A family pedigree. Clin. Genet. 12: 303-313.

Strobel, R.J., Riccardi, V.M., Ledbetter, D.H., and Hittner, H.M. 1980. Duplication 11p11.3 $\rightarrow 14.1$ to meiotic crossing-over. Am. J. Med. Genet. 7: 15-20.

Therkelsen, A.J., Hultén, M., Jonasson, J., Lindsten, J., Christensen, N.C., and Iversen, T. 1973. Presumptive direct insertion within chromosome 2 in man. Ann. Hum. Genet. 36: 367-373.

Wyandt, H.E., Kasprzak, R., Ennis, J., Willson, K., Koch, V., Schnatterly, P., Wilson, W., and Kelly, T.E. 1980 . Interstitial $3 p$ deletion in a child due to paternal paracentric inserted inversion. Am. J. Hum. Genet. 32: 731-735.

\section{Kouji NARAHara}

Department of Pediatrics, Okayama University School of Medicine, Okayama 700, Japan

(Received January 6, 1987)

Jpn. J. Human Genet. 